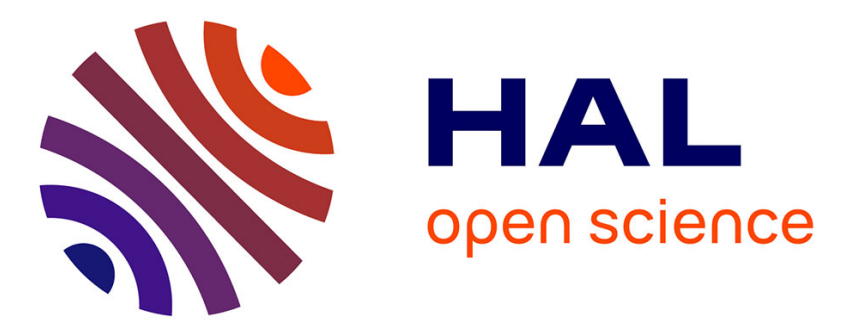

\title{
Combined nutritional stress and a new systemic pesticide (flupyradifurone, Sivanto®) reduce bee survival, food consumption, flight success, and thermoregulation
}

Linda Tong, James C. Nieh, Simone Tosi

\section{To cite this version:}

Linda Tong, James C. Nieh, Simone Tosi. Combined nutritional stress and a new systemic pesticide (flupyradifurone, Sivanto®) reduce bee survival, food consumption, flight success, and thermoregulation. Chemosphere, 2019, 237, pp.124408 -. 10.1016/j.chemosphere.2019.124408 . hal-03487300

\author{
HAL Id: hal-03487300 \\ https://hal.science/hal-03487300
}

Submitted on 20 Dec 2021

HAL is a multi-disciplinary open access archive for the deposit and dissemination of scientific research documents, whether they are published or not. The documents may come from teaching and research institutions in France or abroad, or from public or private research centers.
L'archive ouverte pluridisciplinaire HAL, est destinée au dépôt et à la diffusion de documents scientifiques de niveau recherche, publiés ou non, émanant des établissements d'enseignement et de recherche français ou étrangers, des laboratoires publics ou privés.

\section{(c) (1) $\$$}

Distributed under a Creative Commons Attribution - NonCommerciall 4.0 International 
1 Combined nutritional stress and a new systemic pesticide (flupyradifurone, Sivanto ${ }^{\circledR}$ ) reduce

2 bee survival, food consumption, flight success, and thermoregulation

4 Linda Tong ${ }^{1 *}$, James C. Nieh ${ }^{1}$, Simone Tosi ${ }^{1,2^{*}}$

$6{ }^{1}$ University of California, San Diego, Division of Biological Sciences, Section of Ecology,

7 Behavior, and Evolution. 9500 Gilman Drive, MC0116, La Jolla, CA 92093-0116

$9{ }^{2}$ Epidemiology Unit, European Union Reference Laboratory (EURL) for Honeybee Health,

10 University Paris Est, ANSES (French Agency for Food, Environmental and Occupational Health

11 and Safety) Animal Health Laboratory, 14 rue Pierre et Marie Curie, F94701 Maisons-Alfort,

12 France (present address)

13

$14 *$ Corresponding authors:

15 Simone Tosi: tosi.biology@gmail.com , simone.tosi@anses.fr , +393490610343 (corresponding

16 author handling correspondence)

17 Linda Tong: litong@ucsd.edu

18

19 Other author contact: James Nieh, jnieh@ucsd.edu 


\section{Abstract}

Flupyradifurone (FPF, Sivanto $\left.{ }^{\circledR}\right)$ is a new butenolide insecticide that, like the

23 neonicotinoids, is a systemic nicotinic acetylcholine agonist (nAChR). However, FPF is considered

24 bee-safe (according to standard Risk Assessment tests), and thus a potential solution to the adverse

25 effects of other pesticides on beneficial insects. To date, no studies have examined the impact of

26 nutritional stress (decreased food diversity and quality) and FPF exposure on bee health although

27 both stressors can occur, especially around agricultural monocultures. We therefore tested the

28 effects of a field-realistic FPF concentration ( $4 \mathrm{ppm}, \mathrm{FPF}_{\text {daily dose }}=241 \pm 4 \mathrm{ng} / \mathrm{bee} /$ day, $1 / 12$ of

29 LD 50 ) and nutritional stress (nectar with low-sugar concentrations) on honey bee (Apis mellifera L.)

30 mortality, thermoregulation, flight success (unsuccessful vs. successful), and flight ability (duration,

31 distance, velocity). Flight and thermoregulation are critical to colony health: bees fly to collect food

32 and reproduce, and they thermoregulate to increase flight efficiency and to rear brood. We studied

33 the effects across seasons because seasonality can influence bee sensitivity to environmental stress.

34 We demonstrate that, depending upon season and nutritional stress, FPF can reduce bee survival (-

$3514 \%)$, food consumption (-14\%), thermoregulation (-4\%, i.e. hypothermia), flight success (-19\%),

36 and increase flight velocity $(+13 \%)$. Because pesticide exposure and nutritional stress can co-occur,

37 we suggest that future studies and pesticide risk assessments consider both seasonality and

38 nutritional stress when evaluating pesticide safety for bees.

40 Keywords: seasonality; chronic exposure; bee health; thoracic temperature; food quality; nicotinic 41 acetylcholine receptor $\mathrm{nAChR}$ agonist. 


\section{Introduction}

The honey bee, Apis mellifera L., provides crucial ecosystem services via pollination of

44 native plants and crops worldwide (Potts et al., 2010). However, the health of managed honey bees

45 has decreased globally (Lee et al., 2015; Potts et al., 2010). Large annual losses of managed honey

46 bees are problematic given their role in pollinating crops and native plants and the costs of

47 maintaining healthy bee stocks for agricultural pollination are increasing (Seitz et al., 2015). Recent

48 declines in honey bee colonies may therefore impact crop production costs and perhaps even affect

49 native ecosystems around the globe (Klein et al., 2007).

Factors contributing to recent bee losses include exposure to agricultural chemicals (Henry

51 et al., 2015; Sanchez-Bayo, 2014), environmental variation causing malnutrition (Naug, 2009), and

52 synergistic effects between these factors (Tosi et al., 2017b). Pesticides have received attention

53 because they target pest insects (Jeschke and Nauen, 2008), but can harm beneficial insects. Honey

54 bees may use pesticide-treated crops as a food source and are widely exposed to chemical residues

55 (Tosi et al., 2018) drifting from those (David et al., 2016), which persist in the environment after

56 pesticide use has ceased (Sanchez-Bayo, 2014). In particular, one group of pesticides, the

57 neonicotinoids, have been closely studied for their impact on honey bee health (Pisa et al., 2017;

58 Sanchez-Bayo, 2014).

59 Neonicotinoids act upon the central nervous system of insects as agonists of the nicotinic

60 acetylcholine receptors (nAChRs) and can cause lethal and sublethal effects in bees (Crall et al.,

612019,2018 ; Pisa et al., 2017; Tosi et al., 2017a, 2016; Tosi and Nieh, 2017). Bee flight ability

62 (duration, distance, average velocity, and maximum velocity of flights) is altered by chronic or

63 acute exposure (Tosi et al., 2017a). Blanken et al. (2015) showed that flight ability was reduced by

64 Varroa infestation, and that this effect was stronger in the presence of the neonicotinoid 
65 imidacloprid. Neonicotinoids also alter thermoregulation in honey bees (Tosi et al., 2016) and 66 bumble bees (Crall et al., 2018; Potts et al., 2018), impairing their ability to rewarm after thermal

67 stress (a period of sustained chilling) or to regulate colony temperature. Neonicotinoids can also

68 change bee energy levels (Tosi et al., 2017b) and food consumption (Kessler et al., 2015; Tosi et al., $692017 b$; Tosi and Nieh, 2017).

In response to the concerning effects of neonicotinoids on bees and growing pest resistance,

71 a new generation of pesticides has been developed. Flupyradifurone (FPF), included in commercial

72 formulations like Sivanto ${ }^{\circledR}$, is a butenolide insecticide that is chemically similar to neonicotinoids

73 (Giorio et al., 2017; Nauen et al., 2014). Like neonicotinoids, FPF is systemic and binds to

74 nAChRs, but its bioactivation and structure-activity relationships differ from other nAChR agonists

75 (Jeschke et al., 2015). FPF is effective against sucking pests that are resistant to neonicotinoids, and

76 is used for citrus, cocoa, cotton, grapes, hops, pome fruits, potatoes, soybeans, ornamental plants,

77 and multiple other crops (Nauen et al., 2014).

FPF was reported to have no adverse effects on honey bees, allowing its application via

79 spray on blooming crops with actively foraging bees (Nauen et al., 2014; US EPA, 2014). As part

80 of the registration process for FPF, Risk Assessment (RA) experiments have tested the effects of

81 FPF on honey bees (US EPA, 2014). However, pesticide RA procedures do not thoroughly test the

82 sublethal effects of chemicals (Decourtye et al., 2013). Campbell et al. (Campbell et al., 2016)

83 tested the effects of FPF and observed no significant side-effects on bee colony strength. This latter

84 study, however, shows the difficulty of performing ecotoxicological field trials (Simon-Delso et al.,

85 2017): bee-collected nectar and pollen from control fields were contaminated with FPF.

Tosi et al. (2019) demonstrated that field-realistic worst-case FPF exposures cause sublethal

87 and lethal synergistic effects in bees when combined with a common fungicide (propiconazole), and 
that FPF toxicity varied across season and bee age. Adverse effects on survival and abnormal behaviours began at a field-realistic dose of $375 \mathrm{ng}$ FPF/bee, and FPF was more toxic to foragers compared to in-hive bees, and more toxic to summer bees compared to early spring bees (Tosi and

91 Nieh, 2019). Tan et al. (2015) demonstrated that chronic exposure to FPF impaired olfactory

92 learning in larval (33 ng/larvae/day) and adult (66 ng/adult bee/day) Asian honey bees (Apis

93 cerana). Hesselbach and Scheiner $(2019,2018)$ showed that acute exposure to a high, non-field

94 realistic FPF dose (1200 ng/bee) impaired bee taste, cognition, and motor abilities. However, no

95 studies have yet examined the sublethal effects of FPF on several other factors that influence bee

96 health: food consumption, flight success (being able to fly), flight ability (detailed aspects of flight),

97 and thermoregulation.

98 Flight is essential for pollination services and colony fitness because it allows bees to collect

99 food, to protect the colony, and to reproduce. We therefore used a standard assay of bee flight 100 ability: bees flying in flight mills (Tosi et al., 2017a). Honey bee flight ability depends upon flight 101 muscle temperature (Esch, 1988, 1976; Schmaranzer, 2000; Schmaranzer and Stabentheiner, 1988), 102 which is related to thoracic temperature (Woods et al., 2005). In addition, these flight muscles are a 103 major source of heat production for nest thermoregulation (Bujok et al., 2002; Weidenmüller et al., 104 2002) and during recruitment (Stabentheiner et al., 1995; Stabentheiner and Hagmuller, 1991). Both 105 flight (Tosi et al., 2017a) and heat production (Tosi et al., 2016) are altered by pesticides.

106 Nectar intake provides the energy required for thermoregulation (Gould and Gould, 1988), 107 and thermoregulation and flight ability can depend on nectar sugar concentration (Gmeinbauer and 108 Crailsheim, 1993). The quality of available nectar fluctuates greatly, typically from 5-80\% (w/v) 109 sugar concentration (Abrol, 2012; Crane, 1975), and nectar sugar concentrations can be as low as $1102 \%$ (Abrol, 2012). In agricultural monocultures, decreasing floral diversity may limit the quality of 
111 nectar that bees can access (Donkersley et al., 2014; Naug, 2009) and, consequently, the energy

112 available for flight and thermoregulation. Tosi et al. (2017b) demonstrated that consuming low

113 sucrose nectar containing sublethal field-realistic doses of pesticides could cause adverse

114 synergistic effects on bees by reducing survival, glucose and trehalose hemolymph concentrations, 115 and food consumption.

116 Seasonality can also influence bee sensitivity to environmental stressors, such as pesticides 117 and nutritional stress (Poquet et al., 2016; Tosi and Nieh, 2019). Tosi et al. (2019) demonstrated 118 that FPF is more toxic in summer as compared to early spring. Hesselbach and Scheiner (2019) also 119 observed variations in the effects of FPF depending on the season the bees were collected. Honey 120 bees can adapt to seasonal changes and food scarcity by modifying their foraging range (Schneider 121 and McNally, 1993) and recruitment strategies (Park and Nieh, 2017). Bees are differentially 122 affected by pesticides according to season: following pesticide treatment, winter bees showed 123 higher mortality than summer bees (Decourtye et al., 2003). We therefore considered the effects of 124 two seasons, winter (September to February) and summer (March to August).

125 Our work aimed at providing further insights on the complex and subtle effects that 126 pesticides could elicit on bee behaviour and health. Therefore, we studied the individual and 127 combined effects of FPF, nutrition (rich vs. poor quality diets), and season on survival, 128 thermoregulation (measured as thoracic surface temperature), food consumption, flight success, and 129 flight ability. 
133 (UCSD). We tested 1276 bees from ten healthy honey bee colonies (A. mellifera ligustica Spinola,

134 1806, 10 frames per colony) housed at the UCSD Biology Field Station apiary. We collected

135 foragers that were subsequently exposed to a nutritional stress (ad libitum access to nectar with low 136 sugar concentration) and a pesticide treatment (FPF) across two seasons (winter and summer) using 137 a full factorial design. We applied standard inspection techniques (Dietemann et al., 2013; Higes et 138 al., 2011) to confirm that our colonies were healthy and did not have detectable disease or parasite 139 infestations.

\subsection{Honey bee preparation}

142 We collected returning pollen foragers at their hive entrances, identified as returning bees 143 carrying pollen loads (Henry et al., 2015; Tosi et al., 2017a). The collected foragers were 144 transferred into cages (10 individuals per cage) incubated at $30 \pm 1{ }^{\circ} \mathrm{C}$ and $50-80 \% \mathrm{RH}$ for 3 days, 145 and provided ad libitum sucrose solution through a $5 \mathrm{ml}$ syringe. All bees were chronically exposed 146 to the sucrose solution to simulate exposure over multiple days. The sucrose and pesticide content 147 of the solution varied depending on the sugar diet and FPF treatments (see Methods below), 148 simulating foraging on contaminated fields that produce nectar of poor nutritional quality (lower 149 sugar concentration). Each 24 h, we measured survival and food consumption. After 3 days of 150 incubation, we tested bee thermoregulation and flight. We measured survival once per day, after the 151 thermoregulation and flight measurements, until bee death. Food consumption was measured for 152 bees that were tested in flight mills. Thermoregulation was measured with a randomly selected 153 subset of flown bees. 
In our study, we tested a nutritional stress scenario of limited carbohydrate intake, feeding 157 bees a diet with limited sucrose concentration (the poor diet). We fed bees an ad libitum sugar diet 158 of either rich (50\% w/w sucrose solution) or poor (33\%, leading to a nutritional stress) quality 159 (Crane, 1975; Tosi et al., 2017b). The diet was either pure sucrose solution (control) or contained 160 FPF, depending on the assigned treatment. These nutritional treatments were field-realistic, because 161 foragers can intake these sugar concentrations when ingesting nectar (5-80\%, Abrol, 2012; Crane, 162 1975) or non-ripened honey stored in the nest (Atkins et al., 1975; Crane, 1975). In addition, 163 nutritional stress can also be caused by non-foraging periods. Insufficient food stores are a common 164 cause of winter colony losses (Brodschneider and Crailsheim, 2010; Seitz et al., 2015). More details 165 about the field-realism of the nutritional treatments can be found in Tosi et al. (2017b).

\subsection{FPF treatment}

We followed the most recent international guidelines for pesticide tests on bees

169 (OECD/OCDE, 2017, 1998). Because FPF is a relatively recent pesticide, there is still limited 170 environmental contamination data available (Campbell et al., 2016; US EPA, 2014). However, 171 concentrations of $4.3 \mathrm{ppm}(4300 \mu \mathrm{g} / \mathrm{kg})$ and $4.1 \mathrm{ppm}(4108 \mu \mathrm{g} / \mathrm{kg})$ of FPF were found in the honey 172 stomach of foragers collecting nectar from oilseed rape fields treated with the recommended FPF 173 concentration in France and Northern Germany (US EPA, 2014).

We calculated the worst-case field-realistic FPF oral exposure level for bees following 175 European Food Safety Authority (EFSA) and Environmental Protection Agency (EPA) methods. 176 Foragers collecting nectar in a field previously sprayed with FPF can intake up to 5504 ng FPF/bee 177 per foraging day. According to other calculations (US EPA, 2012), the refined Estimated 
178 Environmental Concentration (EEC) of FPF is $1256 \mathrm{ng} /$ forager for oilseed rape crops (US EPA, 179 2014). When bees forage nectar in cotton fields, refined EEC for workers reaches $6370 \mathrm{ng}$ FPF/bee 180 (US EPA, 2014).

We tested sublethal acute oral exposure to field-realistic concentration and daily doses of

$182 \operatorname{FPF}\left(4 \mu \mathrm{g} / \mathrm{kg}\right.$, corresponding to 4 ppm; $\mathrm{FPF}_{\text {daily dose }}=241 \pm 4 \mathrm{ng} / \mathrm{bee} /$ day $)$. This daily dose was 12.4 183 times lower than the $\mathrm{LD}_{50}$ of FPF (2995 ng/bee, Tosi and Nieh, 2019). The $\mathrm{LD}_{50}$ of FPF calculated 184 during the study period with bees from our study apiary (Tosi and Nieh, 2019) was higher than that 185 reported by US EPA (2014). Similar $\mathrm{LD}_{50}$ variation has been observed for other agonists of insect 186 nAChRs (IRAC Group 4), including the neonicotinoids (EFSA, 2012; Pisa et al., 2014). Our FPF 187 concentration and daily dose were thus field-realistic because bees can consume higher 188 concentrations and daily doses of FPF by ingesting contaminated nectar in the field. Because FPF has a wide spectrum of pest targets and application methods, it can be used 190 across different seasons (Nauen et al., 2014) for agricultural crops and ornamental plants (Nauen et 191 al., 2014) that flower at different times throughout the year, leading to long term exposure. FPF was 192 found in the honey and nectar stored in bee combs for up to five months, and in the nectar collected 193 by foragers for more than two weeks (winter oil seed rape fields, US EPA, 2014).

194 We chronically exposed our bees to FPF for three days. This duration was field-realistic 195 because bees can be exposed to FPF for longer periods in the field (see above). All bees consumed $196 \mathrm{FPF}_{\text {daily doses }}$ that were lower than the dose bees could consume in the field, in part because of the 197 reduced energy requirement of bees confined in cages. This led to low daily consumption doses of 198 sucrose $\left(\right.$ Sucrose $_{\text {daily doses, rich nutrition }}=28.7 \pm 0.4 \mathrm{mg} /$ bee/day, Sucrose $_{\text {daily doses, }}$ poor nutrition $=22.1 \pm 0.3$ $199 \mathrm{mg} / \mathrm{bee} /$ day, calculated on bees tested for flight and thermoregulation $)$ and FPF $\left(\mathrm{FPF}_{\text {daily doses, rich }}\right.$ 200 nutrition $=213 \pm 3 \mathrm{ng} / \mathrm{bee} /$ day, $\mathrm{FPF}_{\text {daily doses, poor nutrition }}=266 \pm 6 \mathrm{ng} / \mathrm{bee} /$ day $)$. 
202 based on ad hoc trials performed for pesticide registration purposes, before product authorization.

203 The estimates of FPF field-realistic doses and concentrations should be updated with more real-

204 world data from multiple scenarios.

We used analytical grade FPF (Sigma Aldrich, CAS\# 951659-40-8, catalog\# 37050-

$206100 \mathrm{MG}$ ) to create our pesticide treatment solutions. Solutions were freshly prepared each week in

$20750 \mathrm{ml}$ tubes with double-distilled water. The tubes were stored at $4^{\circ} \mathrm{C}$ in a dark refrigerator and

208 tightly wrapped in aluminum foil to prevent light degradation.

\subsection{Seasonality}

Season influences bee sensitivity to pesticides (Tosi and Nieh, 2019), and foragers can be

212 exposed to nutritional stress and FPF during different times of the year. We therefore tested field-

213 realistic situations exposing bees to these environmental stresses throughout the year. We

214 categorized our study period into two seasons, winter (September to February) and summer (March

215 to August), to respectively reflect the cool and wet dormant season, and warm and dry growth

216 season that are relevant to bees in our local ecosystem (Park and Nieh, 2017).

\section{$218 \quad 2.5$ Survival: before and after flights}

Bee survival was measured every $24 \mathrm{~h}$ during the 3-day incubation before and after flight

220 testing. After the flight tests, bees were placed in individual cages and fed their respective treatment 221 solutions ad libitum until death. A bee was considered dead when it was immobile and did not react 222 to any stimulation (Medrzycki et al., 2013). 


\subsection{Food consumption}

During the 3-day incubation, we calculated the weight of sucrose and FPF consumed per cage each day, and subsequently calculated the average amount of sucrose and FPF consumed per

227 living bee. In the sugar consumption measurements, we factored the sucrose concentration of the 228 sucrose solutions ( $50 \%$ or $33 \%)$, the density of the sucrose solution $\left(\delta_{50 \% \mathrm{w} / \mathrm{w}}=1229.65 \mathrm{~kg} / \mathrm{m}^{3}, \delta_{33} \%\right.$ $\left.229 \mathrm{w} / \mathrm{w}=1141.51 \mathrm{~kg} / \mathrm{m}^{3}\right)($ Bubnik et al., 1995), the number of live bees per cage per day, and the 230 evaporation rate $(<1 \%)$. To measure the average loss of solution due to evaporation, we kept cages 231 with sucrose solution, but without bees, at the same incubator conditions.

\subsection{Flight success and flight ability}

The flight mills used were described in Tosi et al. (2017), and were based upon the designs

235 of Smith and Jones (2012). Each flight mill consisted of a magnetically levitated, balanced arm 236 upon which the bee flew while surrounded by a white paper cylinder with alternating black and 237 white stripes to provide consistent optic flow. We harnessed each bee as described in Tosi et al. 238 (2017). After harnessing, we rested bees by incubating them individually for $30 \mathrm{~min}\left(30 \pm 1{ }^{\circ} \mathrm{C}\right.$ and $23950-80 \% \mathrm{RH}$ ) before testing them on flight mills. We recorded whether bees completed a successful 240 flight or were not able to fly at all (would not fly even after 10 min of repeated stimulation) ("flight 241 success"). Bees that successfully flew were monitored until exhaustion on the flight mills. For each 242 bee, we used the longest continuous flight during their time in the flight apparatus to calculate flight 243 duration, distance, and velocity ("flight ability"). Each bee was flown only once. 


\subsection{Thermoregulation}

We measured the thoracic surface temperatures of the bees after 3 days of chronic exposure,

247 before and after their flight with an imaging infrared thermography camera (Raytek High-

248 Performance Thermal Imager, ThermoView Ti30, Fluke Process Instruments, Everett, Washington,

249 USA). Infrared thermography is a standard, non-invasive method for measuring bee thoracic surface 250 temperature to estimate honey bee thoracic muscle temperature in ecotoxicological trials (Tosi et 251 al., 2016). Measured temperatures were calibrated with a known temperature source as described in 252 Nieh et al. (2006).

\subsection{Statistical analysis}

We used Fit Proportional Hazards models to test the effect of $\mathrm{FPF}_{\text {daily dose }}$, nutritional stress, 256 season, their interactions, and colony identity upon bee survival before and after the flight test.

257 Significant effects were further analysed with Kaplan-Meier survival analysis (Wilcoxon Chi258 square values).

Nominal Logistic Regression was used to test the effect of FPF, nutritional stress, season,

260 their interactions, and colony on flight success. Significant effects were further analysed with 261 Fisher's Exact test: 2x2, two-tailed, Pearson Chi-square values (Lowry, 2016).

We used Mixed Models (REML algorithm) to test the effects of FPF, nutritional stress, 263 season, and their interactions on food consumption and thermoregulation ability. Colony was used 264 as a random grouping variable. Based upon visual data inspection, effects were further analysed 265 with post-hoc Least-Square Means contrast tests. 
268 ability: duration, distance, average velocity, maximum velocity. Distance and duration were log-

269 transformed to normalize the data. The mixed model allowed testing for both nominal (FPF,

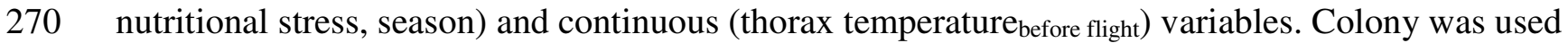

271 as random variable. We used linear regression to further analyze the significant effects of thorax

272 temperature before flight on bee flight ability, computing separate analysis depending on FPF, nutritional

273 stress, and season.

We used JMP Pro v14.0.0 statistical software and applied residuals analyses to confirm the

276 with post- hoc Least-Square Means contrast tests, as appropriate. We used an alpha value of 0.05,

277 but applied the Dunn-Sidak method (Sokal and Rohlf, 1995), as appropriate, to correct for multiple

278 comparisons and indicate tests that pass with ${ }^{\mathrm{DS}}$. We used stepwise model simplification (Crawley,

279 2012). We report mean \pm 1 standard error (s.e.m.). We provide a negative percentage when

280 reporting a percentage decrease and positive percentage to indicate an increase.

282 3. Results

$283 \quad 3.1$ FPF reduced bee survival

284 As expected, bees had higher survival rates when offered higher quality nutrition $(p<0.0001$, Table

285 1). There was a significant effect of season: summer bees survived being caged longer than winter 286 bees $(p=0.012)$. Although there was also no significant effect of $\operatorname{FPF}_{\text {daily dose }}$ alone on survival $(p=$ 287 0.16), the interaction $\mathrm{FPF}_{\text {daily dose }} \times$ season was significant $(p=0.013) . \mathrm{FPF}_{\text {daily dose }}$ reduced bee 288 survival in summer (-14\%, Kaplan-Meier, DF $=1, \chi^{2}=4.46, p=0.035$, Fig. 1). The significant 
289 effects occurred after bee collection, during the chronic exposure to FPF before flight. No

290 significant effects on bee survival were found after flight.

292 Table 1. Summary of the effects of FPF, nutritional stress, and season on bee survival before

293 (during the 3 days incubation) and after the flight tests (Fit proportional hazard test, $N_{\text {before tests }}=$

$2941276 ; N_{\text {after tests }}=338$ ). See Fig. 1 for a graph of the significant results.

\begin{tabular}{clccc} 
Period & \multicolumn{1}{c}{ Factor } & DF & L-R $\boldsymbol{\chi}^{\mathbf{2}}$ & $\boldsymbol{P}$-value \\
\hline \multirow{3}{*}{ Before flight } & FPF daily dose & 1 & 2.00 & 0.157 \\
& Nutritional stress & 1 & 90.42 & $<\mathbf{0 . 0 0 1}$ \\
& Season & 1 & 6.27 & $\mathbf{0 . 0 1 2}$ \\
& FPF $_{\text {daily dose }} \times$ Season & 1 & 6.12 & $\mathbf{0 . 0 1 3}$ \\
& Colony & 10 & 103.08 & $<\mathbf{0 . 0 0 0 1}$ \\
\hline \multirow{3}{*}{ After flight } & FPF daily dose & 1 & 1.30 & 0.255 \\
& Nutritional stress & 1 & 2.85 & 0.092 \\
& Season & 1 & 2.63 & 0.105 \\
& Colony & 10 & 40.24 & $<\mathbf{0 . 0 0 0 1}$ \\
\hline
\end{tabular}

297 Figure 1. Effects $\mathrm{FPF}_{\text {daily dose }}$ on bee survival before flight (during the 3-day incubation) in Winter 298 (left) and Summer (right). The lines are slightly shifted to better display survival trends. More 299 details are reported in Table 1. The asterisk indicates a significant effect (Fit proportional hazards, 300 Kaplan-Meier, $\left.{ }^{*} p<0.05\right)$. 


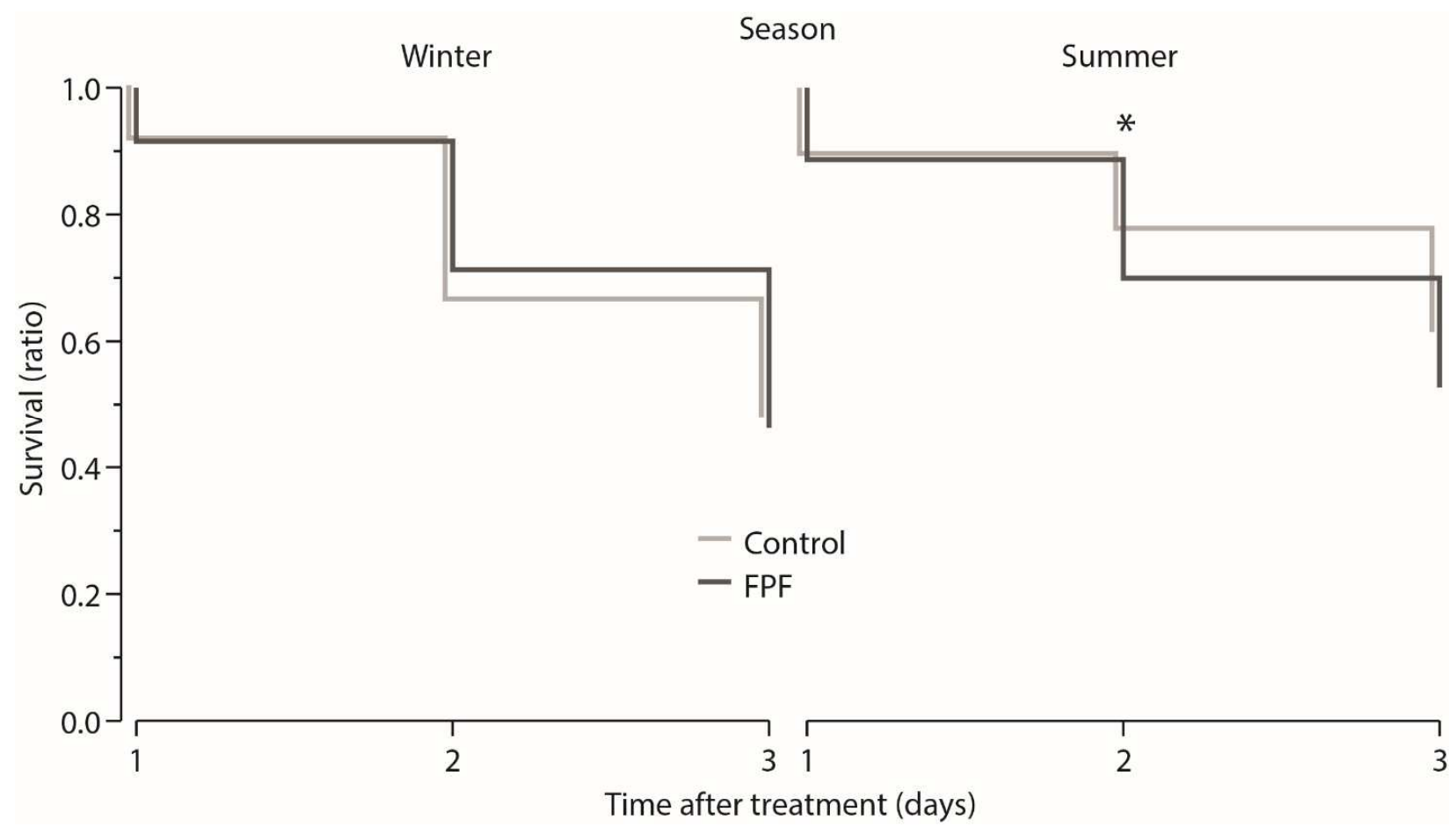

\subsection{Combined FPF and nutritional stresses reduced food consumption}

There was a main significant effect of FPF, nutritional stress, season, and all interactions ( $p$

$306<0.037$, Table 2) on bee food consumption. As expected, nutritional stress reduced the daily

307 consumption of sucrose $\left(-23 \%\right.$, Sucrose daily doses, rich nutrition $=28.7 \pm 0.4 \mathrm{mg} / \mathrm{bee} /$ day, Sucrose $_{\text {daily doses, }}$,

308 poor nutrition $=22.1 \pm 0.3 \mathrm{mg} /$ bee/day, $p<0.0001$ ), and winter bees, characterized by higher energy

309 stores (Ribbands, 1953; Winston, 1987), consumed less sucrose than summer bees $(-9 \%, p=0.001)$.

310 FPF significantly reduced sucrose consumption $(p<0.001)$. Specifically, FPF reduced food

311 consumption of summer (but not winter) bees fed high quality nutrition $\left(-14 \%\right.$, contrast test, $F_{1,327}=$ $312497.63, p<0.0001$, Fig. 2A). The other interactions with FPF did not have any significant effect.

313 As expected, the nutritional treatment altered the consumption of sucrose and FPF, such that

314 bees fed the poor diet (33\% sucrose w/w) ingested a lower mass of sucrose (-23\%, mass of

315 sucrose $_{\text {daily doses, poor nutrition }}=22.1 \pm 0.3 \mathrm{mg} / \mathrm{bee} /$ day, Fig $2 \mathrm{~A}$ and Table 2 ), a greater volume of 
316 sucrose solution ( $+15 \%$, volume of sucrose solution $_{\text {poor } \text { nutrition }}=54.4 \pm 0.8 \mu 1 /$ bee/day), and thus a

317 greater dose of $\mathrm{FPF}\left(+20 \%, \mathrm{FPF}_{\text {daily doses, poor nutrition }}=266 \pm 5 \mathrm{ng} / \mathrm{bee} /\right.$ day $)$ than bees on the rich diet.

319 Table 2. Summary of the effects of FPF, nutritional stress, and season on bee food consumption

320 (sucrose weight intake) over 3 days of incubation (top, Fig. 2A), flight ability (middle, Fig. 2C), and

321 thorax temperature (bottom, before and after flight, Fig. 2D). The REML variance component

322 estimates of colony effect are $55 \%$ for bee food consumption (Mixed Model $_{\text {REML }}, N=338$ ), $\leq 1 \%$

323 for flight ability (Mixed-Model ANCOVAREML, $N=209$ ), and $41 \%$ and $73 \%$ for thorax temperature

324 respectively before and after flight (Mixed Model $_{\text {REML, }} N=234$ ).

\begin{tabular}{|c|c|c|c|c|c|}
\hline Measurement & Factor & $\begin{array}{c}\text { DF } \\
\text { numerator }\end{array}$ & $\begin{array}{c}\text { DF } \\
\text { denominator }\end{array}$ & $F$ ratio & $P$-value \\
\hline \multirow{7}{*}{ Food consumption } & FPF & 1 & 321 & 14.13 & $<0.001$ \\
\hline & Nutritional stress & 1 & 325 & 171.22 & $<0.0001$ \\
\hline & Season & 1 & 328 & 6.78 & 0.010 \\
\hline & FPF $\times$ Nutritional stress & 1 & 323 & 4.38 & 0.037 \\
\hline & FPF $\times$ Season & 1 & 324 & 13.52 & $<0.001$ \\
\hline & Nutritional stress $\times$ Season & 1 & 326 & 12.31 & 0.001 \\
\hline & FPF $\times$ Nutritional stress $\times$ Season & 1 & 324 & 7.71 & 0.006 \\
\hline \multirow{5}{*}{$\begin{array}{l}\text { Flight ability: } \\
\text { Average velocity }\end{array}$} & FPF & 1 & 203 & 1.50 & 0.221 \\
\hline & Nutritional stress & 1 & 190 & 1.47 & 0.227 \\
\hline & Thorax temperature before flight & 1 & 50 & 9.18 & 0.004 \\
\hline & Season & 1 & 46 & 2.19 & 0.146 \\
\hline & FPF $\times$ Season $\times$ Thorax temperature before flight & 1 & 202 & 4.69 & 0.032 \\
\hline \multirow{6}{*}{$\begin{array}{l}\text { Flight ability: } \\
\text { Maximum velocity }\end{array}$} & FPF & 1 & 202 & 1.97 & 0.162 \\
\hline & Nutritional stress & 1 & 192 & 1.45 & 0.230 \\
\hline & Thorax temperature before flight & 1 & 47 & 11.58 & 0.001 \\
\hline & Season & 1 & 48 & 4.15 & 0.047 \\
\hline & FPF $\times$ Nutritional stress $\times$ Season & 1 & 180 & 4.75 & 0.031 \\
\hline & FPF $\times$ Season $\times$ Thorax temperature before flight & 1 & 200 & 6.24 & 0.013 \\
\hline
\end{tabular}




\begin{tabular}{clcccc} 
& FPF & 1 & 204 & 2.69 & 0.102 \\
Flight ability: & Nutritional stress & 1 & 196 & 1.05 & 0.306 \\
Duration & Thorax temperature before flight & 1 & 47 & 1.66 & 0.204 \\
& Season & 1 & 47 & 0.51 & 0.477 \\
\hline & FPF & 1 & 2.48 & 0.117 \\
Flight ability: & Nutritional stress & 1 & 204 & 2.48 \\
Distance & Thorax temperature before flight & 1 & 196 & 1.25 & 0.265 \\
& Season & 1 & 41 & 2.42 & 0.127 \\
\hline \hline \multirow{2}{*}{$\begin{array}{c}\text { Thorax temperature } \\
\text { before flight }\end{array}$} & FPF & 1 & 42 & 0.81 & 0.375 \\
\hline & Nutritional stress & 1 & 226 & 0.04 & 0.836 \\
& Season & 1 & 229 & 0.00 & 0.980 \\
Thorax temperature & Nutritional stress & 1 & 230 & 28.07 & $<0.0001$ \\
\hline after flight & Season & 1 & 223 & 1.88 & 0.172 \\
& FPF $\times$ Nutritional stress & 1 & 224 & 10.50 & $\mathbf{0 . 0 0 1}$ \\
& & 1 & 225 & 87.17 & $<0.0001$ \\
\hline \hline
\end{tabular}


Figure 2. Effect of FPF (4ppm) and diet quality (poor: 33\% sucrose concentration, rich: $50 \%$

327 sucrose concentration) on bee (A) food consumption, (B) flight success, (C) maximum flight

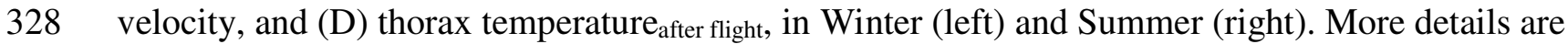

329 reported in Table 2. The asterisks indicate a significant effect (A, B: nominal logistic, Fisher exact

330 test ${ }^{\mathrm{DS}}, * * p<0.01 ; \mathrm{C}, \mathrm{D}$ : Mixed Model ANCOVAREML, contrast test, ${ }^{*} p<0.05$; E, F: Mixed

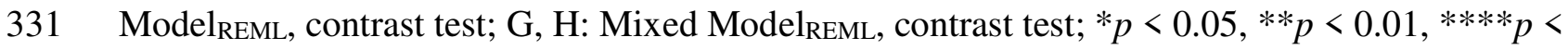

$3320.0001, \mathrm{NS}=$ Not Significant). Error bars show standard errors.

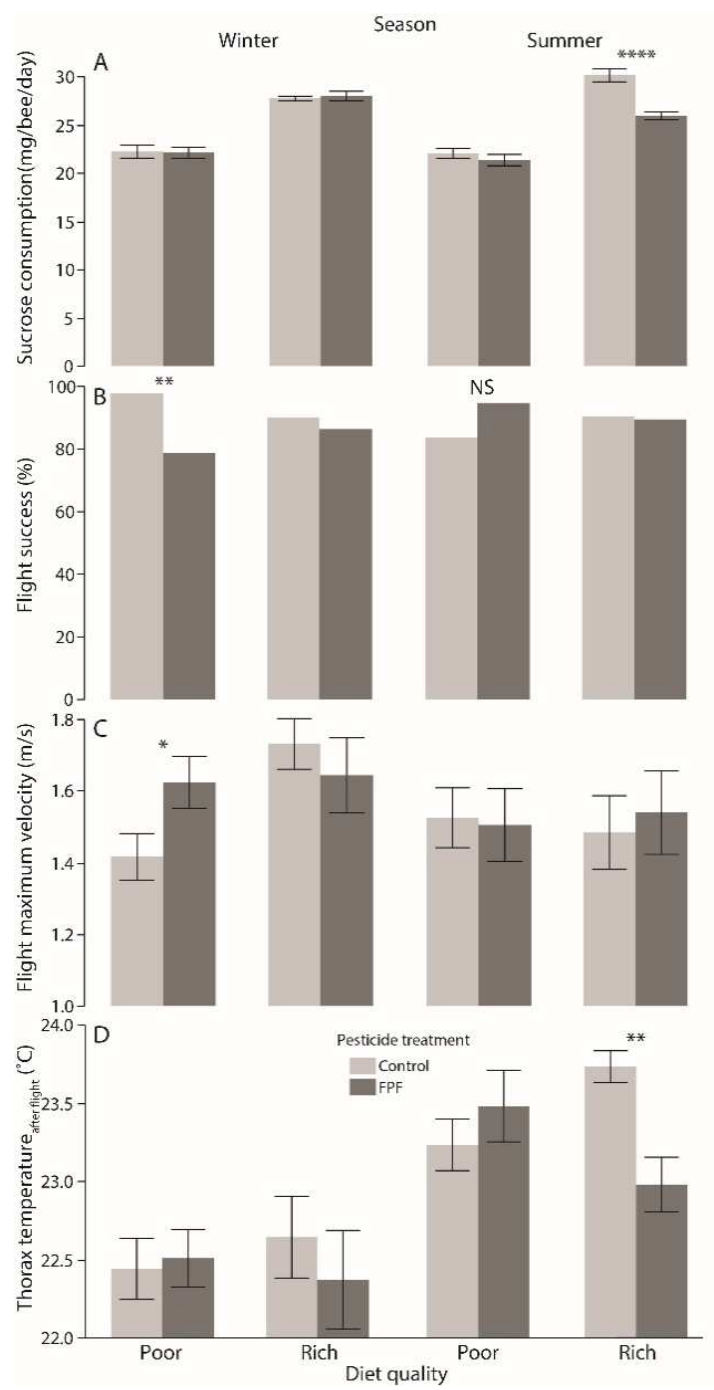


337 However, there was a significant three-way interaction between FPF $\times$ nutritional stress $\times$ season $(p$

$338=0.014)$. FPF reduced the flight success of nutritionally stressed winter bees $(-19 \%$, Fisher Exact 339 test, $\chi^{2}=7.93, p=0.008$, Fig. 2B).

341 Table 3. Summary of the effects of FPF, nutritional stress, and season on bee flight success

342 (Nominal Logistic regression, $N=338$ ). See Fig. 2B for a graph of the significant results.

\begin{tabular}{lccc}
\multicolumn{1}{c}{ Factor } & DF & L-R $\boldsymbol{\chi}^{\mathbf{2}}$ & $\boldsymbol{P}$-value \\
\hline FPF & 1 & 0.57 & 0.452 \\
Nutritional stress & 1 & 0.39 & 0.534 \\
Season & 1 & 0.66 & 0.416 \\
FPF $\times$ Nutritional stress $\times$ Season & 1 & 6.05 & $\mathbf{0 . 0 1 4}$ \\
Colony & 10 & 10.87 & 0.368 \\
\hline
\end{tabular}

There were no significant effects of FPF or nutritional stress on flight ability $(p>0.10$,

348 Table 2). There was only a significant effect of season on maximum velocity $(p=0.047)$. However,

349 the interaction of FPF $\times$ nutritional stress $\times$ season did significantly influence flight maximum

350 velocity $(p=0.031)$. Specifically, FPF significantly increased the maximum flight velocity $(+13 \%)$

351 of winter bees fed the lower quality diet, as compared to control winter bees fed the same diet

352 (contrast test, $F_{1,192}=7.13, p=0.008$, Fig. 2C). 
354 thorax temperature on flight ability. There was a significant effect of thorax temperature before flight 355 upon flight average $(p=0039)$ and maximum $(p<0.001)$ velocity (Table 2$)$. The interaction of FPF

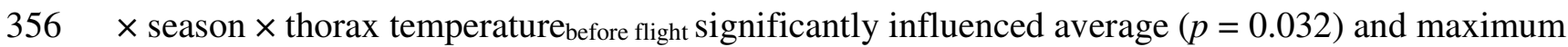
$357(p=0.013)$ flight velocities (Table 2$)$. There was also a significant positive correlation between

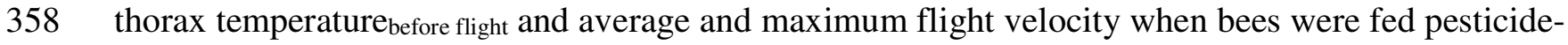
359 free diets of rich quality during the summer $\left(R^{2}>0.29, F_{1,15} \leq 6.64, p \leq 0.025\right)$. Further analyses 360 demonstrated that maximum and average flight velocity correlated positively with thorax 361 temperature before flight $_{\text {when }}$ bees were exposed to both stressors (FPF and nutritional deficiency) in 362 winter $\left(R^{2} \geq 0.25, F_{1,34} \leq 12.13, p \leq 0.002\right)$.

\subsection{Combined FPF and nutritional stresses reduced thorax temperature depending on season}

Summer bees had significantly higher thorax temperatures before and after flight $(p<$ 0.0001, Table 2). Before flight, there were no significant effects of nutrition $(p=0.98)$ or FPF ( $p=$

367 0.84) on bee thorax temperature (Table 2). After flight, there was a significant effect of nutrition $(p$ $368=0.001$ ) on bee thorax temperature such that bees fed the rich diet had a higher thorax temperature 369 than bees fed the poor diet (Table 2). There was no significant effect of FPF alone $(p=0.17)$.

370 However, there was a significant combined effect of FPF and nutritional treatment on bee thorax 371 temperature after flight: specifically, FPF reduced the thorax temperature after flight of summer 372 bees fed the rich diet, as compared to control summer bees fed the same diet $\left(-4 \%,-1^{\circ} \mathrm{C}\right.$, contrast 373 test, $\mathrm{F}_{1,221}=6.90, p=0.009$, Fig. 2D). 


\section{Discussion}

We demonstrate, for the first time, that field-realistic nutritional stress and FPF can,

377 individually and in combination, impair bee health through lethal and sublethal effects. These

378 effects are influenced by season. Our work highlights how the effects of pesticides can be subtle

379 and are often only revealed as an interaction with other factors, such as nutritional status, season, 380 and flight exertion.

381 FPF reduced bee thermoregulation ability after flight $\left(-1^{\circ} \mathrm{C},-4 \%\right.$, Table 2, Fig. 2D), a high 382 intensity task (Beenakkers et al., 1984). Before flight, there was no effect of nutritional stress or 383 FPF on bee thorax temperature, confirming the low sublethal levels of the tested treatments.

384 However, after summer flights, the combination of FPF and nutritional treatment did alter bee 385 thorax temperature. FPF reduced the thorax temperature after flight of summer bees fed the rich 386 diet, compared to pesticide-free bees exposed to the rich diet (Fig. 2D). We hypothesize that the 387 interaction of rich diet and FPF have elicited behavioural and physiological responses in the short388 term (i.e. increased thermogenesis, motor activity, hyperactivity; Potts et al 2018, Tosi et al 2016, 389 Tosi and Nieh, 2019) that led to higher exertion and energy exploitation as compared to the poor 390 nutritional treatment, which caused hypothermia (lower body temperature) in the longer-term, after 391 flight (Fig. 2D). We speculate that the nutritionally deficient poor diet may have halted the 392 increased activity elicited in summer bees fed the rich diet and FPF. requirements (Tosi et al., 2017b), perhaps due to detoxification demands, to changes in bee energy metabolism (du Rand et al., 2017), or both. Although FPF may increase energy consumption, FPF396 treated bees did not increase their sucrose consumption, similar to the results found for bees 397 exposed to neonicotinoids (Kessler et al., 2015; Tosi and Nieh, 2017). It is unclear why this is the 
case, but these pesticides may have broad effects given that they target a common receptor found in

399 multiple neuron types and influence multiple behaviours such as feeding. The extremely energy-

400 intensive behavior of bees flying to exhaustion likely revealed the subtle combined effect of

401 pesticide and nutritional stress upon bee thermoregulation after flight.

This impairment may have other consequences. Flight muscles are in the thorax and are a major source of shivering thermogenesis in bees (Heinrich and Esch, 1994; Roberts and Harrison,

404 1998). Thus, the reduction of bee thermoregulation ability after flight can impair colony fitness

405 because bees need to thermoregulate while unloading their collected food or waggle dancing to

406 recruit nestmates after returning to the colony (Stabentheiner et al., 1995; Stabentheiner and 407 Hagmuller, 1991).

Field-realistic exposure to FPF reduced forager survival. These effects were influenced by 409 season: FPF reduced bee survival in summer (-14\%, Table 1, Fig. 1), confirming a prior study 410 showing that FPF toxicity increases in summer (Tosi and Nieh, 2019).

411 FPF reduced food consumption (-14\%) of bees reared at optimal conditions (rich nutrition,

412 summer, Fig. 2A). Bees that were fed poor nutrition consumed a greater volume of solution (+15\%, 413 perhaps because of hunger), thus increasing their consumption of FPF (+20\%; mean and s.e.m.: 266 $414 \pm 5 \mathrm{ng} / \mathrm{bee}$ ), as compared to bees fed rich nutrition. Consequently, in field-realistic scenarios of 415 pesticide contamination, bees that are malnourished or exposed to low-quality nutrition could face 416 an amplified risk due to increased pesticide exposure. This scenario is concerning, given that 417 pesticides and nutritional stress have adverse synergistic effects on bees (Tosi et al., 2017b). $418 \quad$ Nutritionally stressed bees became satiated before daily caloric needs were met. Although 419 the nutritional stress increased the volume of sucrose solution consumed as expected $(+15 \%$, 420 sucrose solution volume poor nutrition $=54.4 \pm 0.8 \mu 1 /$ bee/day $)$, sucrose intake was still lower $(-23 \%$, 


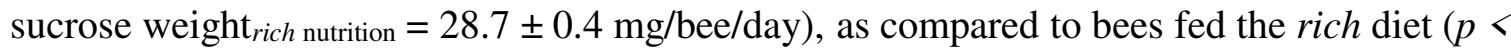
0.0001, Table 2, Fig. 2A). These findings support previous results, demonstrating that sucrose solution satiation occurs at $64 \pm 1 \mu \mathrm{l} /$ bee/day (Tosi et al., 2017b). We also showed that winter bees, characterized by higher energy stores (Mattila et al., 2001; Ribbands, 1953), required less sucrose than summer bees $(p=0.010)$.

The combined field-realistic exposure to FPF and nutritional stress reduced flight success in 427 winter bees (-19\%, Table 2, Fig. 2B). The rich nutrition seemed to buffer the effect of FPF on flight 428 success. Conversely, the poor nutrition diet was not enough to protect winter bees from the adverse 429 effects of FPF, perhaps because nutritional stress and pesticides act synergistically to reduce bee 430 health and energy levels (Tosi et al., 2017b), and toxin detoxification requires energy (du Rand et 431 al., 2017). Foraging flights are essential to collect food for the hive (Riley et al., 2005), and 432 impairing flight success should reduce colony fitness. Flight ability was altered by combined exposure to FPF and nutritional stress, and these 434 effects were influenced by season and bee body temperature before flight (Table 2, Fig. 2C). The 435 increased maximum velocity of flights $(+13 \%)$ caused by FPF may be a kind of hyperactivity, a 436 typical short-term effect of FPF (Tosi and Nieh, 2019) and nicotinic acetylcholine receptor 437 (nAChRs) agonists (Gill and Raine, 2014; Tosi et al., 2017a; Tosi and Nieh, 2017). This alteration 438 was only significant in winter bees exposed to a concomitant nutritional stress. Chronic nutritional stress alone did not significantly influence flight ability ( $p \geq 0.23$ ).

440 Sucrose concentration (1-4 M, feeding a single dose) is known to positively correlate with the speed 441 of bees in flight mills (Balderrama et al., 1992; Gmeinbauer and Crailsheim, 1993). Because we fed 442 bees continuously over multiple days, they may have built up their flight reserves, buffering the 443 effects of our nutritional stress. Another possibility is that nutritional stress in conjunction with 
444 pesticide exposure reduced bee survival before flight, leaving only the more resistant and healthy 445 bees for flight testing.

446 Winter and summer bees differ in multiple ways. Summer bees usually spend more time 447 flying and less time thermoregulating as compared to winter bees (Mattila et al., 2001; Rortais et al., 448 2005). Summer bees also have reduced energy stores, longevity, and are less resistant to multiple 449 stressors (Ribbands, 1953; Winston, 1987) including pesticides (Decourtye et al., 2003; Tosi and 450 Nieh, 2019). We found that FPF reduced survival, food consumption, and thermoregulation of 451 summer bees, which have less robust survival, food stores, and thermoregulatory abilities than 452 winter ones (Mattila et al., 2001). Similarly, FPF reduced flight success and altered flight ability in 453 winter bees, which may fly less, as compared to summer bees (Mattila et al., 2001; Rortais et al., 454 2005). These results support prior data demonstrating that FPF toxicity changes across season (Tosi 455 and Nieh, 2019).

We also show that bees with warmer flight muscles flew faster, as expected (Table 2). These 457 higher thoracic temperatures should increase the ability of bees to fly and thereby to retrieve food 458 (Woods et al., 2005). We captured these effects at different situations, when bees were exposed to 459 both good (summer pesticide-free foragers fed higher sugar content diets) and sub-optimal (winter 460 bees fed lower sugar content diets with pesticide) conditions. Because our bees were not the exact 461 same age, this may have affected our experimental outcomes such as increasing variance in our 462 measured effects. However, all tested bees belonged to the foraging caste and were therefore in the 463 same age group, and studying foragers as an overall group has relevance for understanding the real464 world impact of pesticides

465 As with other relatively new pesticides, the contamination levels of FPF in the environment 466 are largely unknown, especially for winter bees. Further screening of environmental contamination 
467 following real-world use of pesticides over a broad spectrum of environmental conditions

468 (including across seasons) is crucial for appropriately assessing actual residue levels and consequent

469 pesticide risk. Nonetheless, independently from the estimation of field-realism, our work

470 demonstrates how pesticide toxicity varies depending on multiple environmental factors.

471 Our results align with recent research showing that FPF, examined as a single factor, has

472 little or no adverse effects on honey bees (Campbell et al., 2016; Hesselbach and Scheiner, 2019,

473 2018; Tosi and Nieh, 2019). However, field-realistic levels of FPF can synergistically impair $A$.

474 mellifera survival and behaviour when combined with another pesticide, and FPF toxicity is

475 significantly influenced by season and worker type (Tosi and Nieh, 2019). Field-realistic FPF

476 exposure alone can also impair cognition in an Asian honey bee species, Apis cerana (Tan et al.,

477 2015). Tosi et al. (2017b) also demonstrate that pesticides interact with non-pesticide field-realistic

478 stressors, such as nutritional stress (e.g. starvation), to alter bee health. When seasonality and

479 nutritional stress were examined, our study found that FPF altered bee survival, food consumption,

480 flight, and thermoregulation. We thus provide further insights on the complex and subtle effects that

481 pesticides elicit on bee behaviour. These sublethal effects may impair colony health. Future studies

482 - in the lab and in the field - should therefore holistically examine multiple factors and bee

483 behaviours, and consider the role that seasonality and nutritional stress play in pesticide toxicity. 484

Appendix A. Supplementary data

Data are available from Zenodo: 10.5281/zenodo.2811565 
The authors declare no competing financial interests.

\section{Author contributions}

ST and JCN conceived the experiments. ST, LT, and JCN designed the experiments. LT

493 performed the experiments, collected and managed all data. JCN provided materials and reagents.

494 ST, LT, and JCN analysed the data. ST, LT, and JCN wrote and reviewed the manuscript.

496 Acknowledgements

497 We would like to thank Joseph Di Liberto, Kevin Hsiung, and the multiple students who 498 contributed to this research. This research was partially funded by the UCSD Academic Senate and 499 the Avaaz foundation, which have no influence on the research design, collection, data analysis, 500 data interpretation and manuscript writing or publication.

503 Abrol, D.P., 2012. Pollination biology. Biodiversity Conservation and Agricultural Production. $504 \quad$ Springer Publication, UK.

505 Atkins, E.L., Banker, R., Butler, C.G., Cale, G.H., Cale Jr, G.H., Crane, E., Dadant, C.C., 1975.

506 Gathering, storing and ripening nectar, in: Graham, J.M. (Ed.), The Hive and the Honey Bee. 
Dadant \& Sons, Hamilton, p. 1324.

508 Balderrama, N.M., de Almeida, L.O.B., Núñez, J.A., 1992. Metabolic rate during foraging in the honeybee. J. Comp. Physiol. B 162, 440-447. https://doi.org/10.1007/bf00258967

Beenakkers, A.M.T.M.T., Van der Horst, D.J.J., Van Marrewijk, W.J.A.J.A., 1984. Insect flight muscle metabolism. Insect Biochem. 14, 243-260. https://doi.org/10.1016/00201790(84)90057-X 
bumblebee nest behavior, social networks, and thermoregulation. Science (80). 686, 683-686.

531 Crane, E., 1975. Honey. A comprehensive survey. Heinemann, London.

532 Crawley, M.J., 2012. Statistical Modelling, in: The R Book, Second Edition. pp. 388-448. https://doi.org/10.1002/9781118448908.ch9

534 David, A., Botías, C., Abdul-Sada, A., Nicholls, E., Rotheray, E.L., Hill, E.M., Goulson, D., 2016. Widespread contamination of wildflower and bee-collected pollen with complex mixtures of neonicotinoids and fungicides commonly applied to crops. Environ. Int. 88, 169-178. https://doi.org/10.1016/j.envint.2015.12.011

Decourtye, A., Henry, M., Desneux, N., 2013. Overhaul pesticide testing on bees. Nature 497, 188. https://doi.org/10.1038/497188a

540 Decourtye, A., Lacassie, E., Pham-Delegue, M.-H., 2003. Learning performances of honeybees (Apis mellifera $\mathrm{L}$ ) are differentially affected by imidacloprid according to the season. Pest Manag. Sci. 59, 269-278. https://doi.org/10.1002/ps.631

Dietemann, V., Nazzi, F., Martin, S.J., Anderson, D.L., Locke, B., Delaplane, K.S., Wauquiez, Q., Tannahill, C., Frey, E., Ziegelmann, B., Rosenkranz, P., Ellis, J.D., 2013. Standard methods for varroa research. J. Apic. Res. 52, 1-54. https://doi.org/10.3896/IBRA.1.52.1.09

Donkersley, P., Rhodes, G., Pickup, R.W., Jones, K.C., Wilson, K., 2014. Honeybee nutrition is linked to landscape composition. Ecol. Evol. 4, 4195-4206. https://doi.org/10.1002/ece3.1293 du Rand, E.E., Pirk, C.W.W., Nicolson, S.W., Apostolides, Z., W. W. Pirk, C., Nicolson, S.W., Apostolides, Z., 2017. The metabolic fate of nectar nicotine in worker honey bees. J. Insect Physiol. 98, 14-22. https://doi.org/10.1016/j.jinsphys.2016.10.017

EFSA, 2012. Scientific Opinion on the science behind the development of a risk assessment of Plant Protection Products on bees (Apis mellifera, Bombus spp and solitary bees). EFSA J. 10, 
554 Esch, H., 1988. The effects of temperature on flight muscle potentials in honeybees and cuculiinid winter moths. J. Exp. Biol. 135, 109-117.

556 Esch, H., 1976. Body temperature and flight performance of honey bees in a servo-mechanically controlled wind tunnel. J. Comp. Physiol. A 109, 265-277. https://doi.org/10.1007/BF00663608

Gill, R.J., Raine, N.E., 2014. Chronic impairment of bumblebee natural foraging behaviour induced by sublethal pesticide exposure. Funct. Ecol. 28, 1459-1471. https://doi.org/10.1111/1365-

562 Giorio, C., Safer, A., Sánchez-Bayo, F., Tapparo, A., Lentola, A., Girolami, V., Bijleveld van Lexmond, M., Bonmatin, J.-M., 2017. An update of the Worldwide Integrated Assessment (WIA) on systemic insecticides. Part 1: new molecules, metabolism, fate, and transport.

Gould, J.L., Gould, C.G., 1988. The Honey Bee. Scientific American Library, New York.

Heinrich, B., Esch, H., 1994. Thermoregulation in bees. Am. Sci. 82, 164-170.

Henry, M., Cerrutti, N., Aupinel, P., Decourtye, A., Gayrard, M., Odoux, J.-F.F., Pissard, A., Rüger, C., Bretagnolle, V., 2015. Reconciling laboratory and field assessments of neonicotinoid toxicity to honeybees. Proc. R. Soc. B Biol. Sci. 282, 20152110. https://doi.org/10.1098/rspb.2015.2110

Hesselbach, H., Scheiner, R., 2019. The novel pesticide flupyradifurone (Sivanto) affects honeybee motor abilities. Ecotoxicology 1-6. https://doi.org/10.1007/s10646-019-02028-y 
Hesselbach, H., Scheiner, R., 2018. Supplementary information of Effects of the novel pesticide flupyradifurone (Sivanto) on honeybee taste and cognition. Sci. Rep. 8, 4954. https://doi.org/10.1038/s41598-018-23200-0

Higes, M., Nozal, M.J., Alvaro, A., Barrios, L., Meana, A., Martín-Hernández, R., Bernal, J.L., Bernal, J., 2011. The stability and effectiveness of fumagillin in controlling Nosema ceranae (Microsporidia) infection in honey bees (Apis mellifera) under laboratory and field conditions. Apidologie 42, 364-377. https://doi.org/10.1007/s13592-011-0003-2

Jeschke, P., Nauen, R., 2008. Neonicotinoids-from zero to hero in insecticide chemistry. Pest Manag. Sci. 64, 1084-98. https://doi.org/10.1002/ps.1631

Jeschke, P., Nauen, R., Gutbrod, O., Beck, M.E., Matthiesen, S., Haas, M., Velten, R., 2015. Flupyradifurone (Sivanto ${ }^{\mathrm{TM}}$ ) and its novel butenolide pharmacophore: Structural considerations. Pestic. Biochem. Physiol. 121, 31-38. https://doi.org/10.1016/j.pestbp.2014.10.011

Kessler, S.C., Tiedeken, E.J., Simcock, K.L., Derveau, S., Mitchell, J., Softley, S., Stout, J.C., Wright, G.A., 2015. Bees prefer foods containing neonicotinoid pesticides. Nature 521, 74-76. https://doi.org/10.1038/nature14414

Klein, A.-M., Vaissière, B.E., Cane, J.H., Steffan-Dewenter, I., Saul, A., Kremen, C., Tscharntke, T., B, P.R.S., Vaissie, B.E., Cunningham, S. a, Kremen, C., Tscharntke, T., 2007. Importance of pollinators in changing landscapes for world crops. Proc. Biol. Sci. 274, 303-313. https://doi.org/10.1098/rspb.2006.3721

Lee, K. V., Steinhauer, N., Rennich, K., Wilson, M.E., Tarpy, D.R., Caron, D.M., Rose, R., Delaplane, K.S., Baylis, K., Lengerich, E.J., Pettis, J., Skinner, J.A., Wilkes, J.T., Sagili, R., VanEngelsdorp, D. 2015. A national survey of managed honey bee 2013-2014 annual colony 
losses in the USA. Apidologie 46, 292-305. https://doi.org/10.1007/s13592-015-0356-z

Lowry, R., 2016. VassarStats: Website for Statistical Computation [WWW Document]. URL http://vassarstats.net/fisher2x3.html

602

Mattila, H.R., Harris, J.L., Otis, G.W., 2001. Timing of production of winter bees in honey bee (Apis mellifera) colonies. Insectes Soc. 48, 88-93. https://doi.org/10.1007/PL00001764

Medrzycki, P., Giffard, H., Aupinel, P., Belzunces, L.P., Chauzat, M.-P., Claßen, C., Colin, M.E., Porrini, C., Schur, A., Sgolastra, F., Delso, N.S., van der Steen, J.J.M., Wallner, K., Alaux, C., Biron, D.G., Blot, N., Bogo, G., Brunet, J.-L., Delbac, F., Diogon, M., El Alaoui, H., Provost, B., Tosi, S., Vidau, C., 2013. Standard methods for toxicology research in Apis mellifera. J. Apic. Res. 52, 1-60. https://doi.org/10.3896/IBRA.1.52.4.14

Nauen, R., Jeschke, P., Velten, R., Beck, M.E., Ebbinghaus-Kintscher, U., Thielert, W., Wolfel, K., Haas, M., Kunz, K., Raupach, G., Wölfel, K., Haas, M., Kunz, K., Raupach, G., Wolfel, K., Haas, M., Kunz, K., Raupach, G., Wölfel, K., Haas, M., Kunz, K., Raupach, G., 2014. Flupyradifurone: a brief profile of a new butenolide insecticide. Pest Manag. Sci. 71, n/a-n/a. https://doi.org/10.1002/ps.3932

Naug, D., 2009. Nutritional stress due to habitat loss may explain recent honeybee colony collapses. Biol. Conserv. 142, 2369-2372. https://doi.org/10.1016/j.biocon.2009.04.007

Nieh, J.C., Leon, A., Cameron, S., Vandame, R., 2006. Hot bumble bees at good food: thoracic temperature of feeding Bombus wilmattae foragers is tuned to sugar concentration. $\mathrm{J}$ Exp Biol 209, 4185-4192. https://doi.org/10.1242/jeb.02528

OECD/OCDE, 2017. OECD guideline 245 for the testing of chemicals. Honey bee (Apis mellifera L.), chronic oral toxicity test (10-day feeding), OECD/OCDE, OECD Guidelines for the 
Testing of Chemicals, Section 2. OECD Publishing. https://doi.org/10.1787/9789264284081-

en

624 OECD/OCDE, 1998. OECD Guideline 213 for the testing of chemicals: honeybees, acute oral toxicity test. https://doi.org/10.1787/9789264070165-en

626 Park, B., Nieh, J.C., 2017. Seasonal trends in honey bee pollen foraging revealed through DNA barcoding of bee-collected pollen. Insectes Soc. 64, 425-437. https://doi.org/10.1007/s00040017-0565-8

Pisa, L., Goulson, D., Yang, E.-C.C., Gibbons, D., Sánchez-Bayo, F., Mitchell, E., Aebi, A., van der Sluijs, J., MacQuarrie, C.J.K.K., Giorio, C., Long, E.Y., McField, M., Bijleveld van Lexmond, M., Bonmatin, J.-M.M., Gibbon, D., Sánchez-Bayo, F., Mitchell, E., Aebi, A., Sluijs, J. van der, MacQuarrie, C.J.K.K., Giorio, C., Long, E.Y., McField, M., Lexmond, M.B. van, Bonmatin, J.-M.M., 2017. An update of the Worldwide Integrated Assessment (WIA) on systemic insecticides. Part 2: impacts on organisms and ecosystems. Environ. Sci. Pollut. Res. 1-33. https://doi.org/10.1007/s11356-017-0394-3

Pisa, L.W., Amaral-Rogers, V., Belzunces, L.P., Bonmatin, J.M., Downs, C.A., Goulson, D., Kreutzweiser, D.P., Krupke, C., Liess, M., McField, M., Morrissey, C.A., Noome, D.A., Settele, J., Simon-Delso, N., Stark, J.D., Van Der Sluijs, J.P., Van Dyck, H., Wiemers, M., 2014. Effects of neonicotinoids and fipronil on non-target invertebrates. Environ. Sci. Pollut. Res. Int. 22, 68-102. https://doi.org/10.1007/s11356-014-3471-x

Poquet, Y., Vidau, C., Alaux, C., 2016. Modulation of pesticide response in honeybees. Apidologie 1-15. https://doi.org/10.1007/s13592-016-0429-7

Potts, R., Clarke, R.M., Oldfield, S.E., Wood, L.K., Hempel de Ibarra, N., Cresswell, J.E., 2018. The effect of dietary neonicotinoid pesticides on non-flight thermogenesis in worker bumble 
bees (Bombus terrestris). J. Insect Physiol. 104, 33-39. https://doi.org/10.1016/j.jinsphys.2017.11.006

Potts, S.G., Biesmeijer, J.C., Kremen, C., Neumann, P., Schweiger, O., Kunin, W.E., 2010. Global pollinator declines: Trends, impacts and drivers. Trends Ecol. Evol. 25, 345-353. https://doi.org/10.1016/j.tree.2010.01.007

650 Ribbands, C.R., 1953. The Bahavior and Social Life of Honeybees.

651 Riley, J.R., Greggers, U., Smith, A.D., Reynolds, D.R., Menzel, R., 2005. The flight paths of 652 honeybees recruited by the waggle dance. Nature 435, 205-207.

653 Roberts, S.P., Harrison, J.F., 1998. Mechanisms of Thermoregulation in Flying Bees. Integr. Comp. 654 Biol. 38, 492-502. https://doi.org/10.1093/icb/38.3.492

Rortais, A., Arnold, G., Halm, M.-P., Touffet-Briens, F., 2005. Modes of honeybees exposure to systemic insecticides: estimated amounts of contaminated pollen and nectar consumed by different categories of bees. Apidologie 36, 71-83. https://doi.org/10.1051/apido:2004071

660 Schmaranzer, S., 2000. Thermoregulation of water collecting honey bees (Apis mellifera). J Insect $661 \quad$ Physiol 46, 1187-1194.

662 Schmaranzer, S., Stabentheiner, A., 1988. Variability of the thermal behavior of honeybees on a 663 feeding place. J. Comp. Physiol. B 158, 135-141. https://doi.org/10.1007/BF01075826 664 Schneider, S.S., McNally, L.C., 1993. Spatial foraging patterns and colony energy status in the 665 African honey bee, Apis mellifera scutellata. J. Insect Behav. 6, 195-210.

666 https://doi.org/10.1007/bf01051504

667 Seitz, N., Traynor, K.S., Steinhauer, N., Rennich, K., Wilson, M.E., Ellis, J.D., Rose, R., Tarpy, 
D.R., Sagili, R.R., Caron, D.M., Delaplane, K.S., Rangel, J., Lee, K., Baylis, K., Wilkes, J.T., Skinner, J.A., Pettis, J.S., VanEngelsdorp, D., 2015. A national survey of managed honey bee 2014-2015 annual colony losses in the USA. J. Apic. Res. 54, 1-12. https://doi.org/10.1080/00218839.2016.1153294

Simon-Delso, N., San Martin, G., Bruneau, E., Delcourt, C., Hautier, L., 2017. The challenges of predicting pesticide exposure of honey bees at landscape level. Sci. Rep. 7, 3801. https://doi.org/10.1038/s41598-017-03467-5

Smith, T., Jones, V.P., 2012. The Flight Mill [WWW Document].

Sokal, R.R., Rohlf, F.J., 1995. Biometry: the principles and practice of statistics in biological research. WH Freman and company: New York.

Stabentheiner, A., Hagmuller, K., 1991. Sweet food means "Hot Dancing" in honeybees. Naturwissenschaften 78, 471-473. https://doi.org/10.1007/BF01134389

Stabentheiner, A., Kovac, H., Hagmuller, K., 1995. Thermal behavior of round and wagtail dancing honeybees. J. Comp. Physiol. B 165, 433-444. https://doi.org/10.1007/BF00261297

Tan, K., Chen, W., Dong, S., Liu, X., Wang, Y., Nieh, J.C., 2015. A neonicotinoid impairs olfactory learning in Asian honey bees (Apis cerana) exposed as larvae or as adults. Sci. Rep. 5, 2-10. https://doi.org/10.1038/srep10989

Tosi, S., Burgio, G., Nieh, J.C.J.C., 2017a. A common neonicotinoid pesticide, thiamethoxam, impairs honey bee flight ability. Sci. Rep. 7, 1201. https://doi.org/10.1038/s41598-017-013618

Tosi, S., Costa, C., Vesco, U., Quaglia, G., Guido, G., 2018. A 3-year survey of Italian honey beecollected pollen reveals widespread contamination by agricultural pesticides. Sci. Total Environ. 615, 208-218. https://doi.org/10.1016/j.scitotenv.2017.09.226 
691 Tosi, S., Démares, F.J., Nicolson, S.W., Medrzycki, P., Pirk, C.W.W., Human, H., Demares, F.J., 692 Nicolson, S.W., Medrzycki, P., Pirk, C.W.W., Human, H., Démares, F.J., Nicolson, S.W.,

711 Winston, M.L., 1987. Biology of the Honey Bee. Harvard University Press, Cambridge, MA.

712 Woods, W. a, Heinrich, B., Stevenson, R.D., 2005. Honeybee flight metabolic rate: does it depend 713 
Pesticide (control vs. FPF)

Nutritional

Stress

(rich vs. poor diet)

\section{Season}

(summer vs. winter)

\section{$\downarrow$ Survival}

\section{$\downarrow$ Food consumption}

Flight

$\downarrow$ Success $\uparrow$ Velocity

$\downarrow$ Thermoregulation 